\title{
Immigration to the US: The Insidious Health Risk Factor
}

\author{
Camille Clarke ${ }^{1,5}$, Maud Joachim-Célestin ${ }^{2,5}$, Brenda Rea ${ }^{3,4}$, Marisol Lara ${ }^{4,5}$ and Susanne B. Montgomery ${ }^{5}$ \\ 1. School of Medicine, Loma Linda University, Loma Linda, CA 92374, USA \\ 2. Department of Preventive Medicine, Loma Linda University, Loma Linda, CA 92354, USA \\ 3. Department of Family Medicine, Loma Linda University Health, Loma Linda, CA 92354, USA \\ 4. School of Public Health, Loma Linda University, Loma Linda, CA 92354, USA \\ 5. School of Behavioral Health, Loma Linda University, Loma Linda, CA 92354, USA
}

\begin{abstract}
US Latinos experience higher rates of obesity than their non-Latino counterparts. Factors associated with immigration, including length of residence in the United States, are associated with an increased risk of obesity. Latino community health workers (CHWs) work closely with communities, and are in an ideal position to provide insight on the underlying mechanisms of the Latino obesity epidemic. Focus groups were conducted with $15 \mathrm{CHWs}$ and thematic analyses were performed to explore elements associated with obesity among Latino immigrants. Emergent themes included: reduction in physical activity due to less walkable spaces, more transportation options, and busier schedules in the United States. Interviewees also identified a sudden increase in access to unhealthy food and an abrupt reduction in access to, and affordability of, healthy food choices upon immigration. Culturally appropriate interventions to increase awareness of these factors and neutralize their effects among early Latino immigrants are recommended.
\end{abstract}

Key words: Immigrant health, lifestyle, obesity, community health workers, qualitative research.

\section{Introduction}

The obesity epidemic in the United States has disproportionately affected racial and ethnic minority populations. Latinos, the fastest growing minority group in the United States, have one of the highest rates of obesity (42.5\%), exceeded only by non-Hispanic blacks (48.1\%) [1]. This high rate contributes to higher national rates of obesity-related illnesses such as type 2 diabetes (T2D), cardiovascular disease, and hypertension that is particularly acute among Latino immigrants [2].

Genetics and lifestyle behaviors, such as lack of physical activity and unhealthy eating patterns, are often considered risks factors for obesity. However, recent immigrants to the United States are known to have lower BMI and a "health advantage," compared to those of the same culture who were born in this country [3]. Recent evidence shows that Latino

Corresponding author: Camille Clarke, MD, FACP, research fields: lifestyle medicine, obesity, health disparities, health education and culturally-adapted healthcare. immigrants have an increasing incidence of obesity as their residence in the United States continues [4-6]. The health advantage seems to disappear 10-15 years after immigration.

The growing trend of Latino immigration (34.4\%), and widespread prevalence of obesity among Latinos, makes culturally appropriate weight-loss strategies vitally important $[7,8]$. However, limited studies on obesity among Latino populations have evaluated the role that immigration plays in the adoption of obesogenic behaviors. One involved a weight-loss intervention among immigrants living on the East Coast, using the Health at Every Size (HAES) model [9-11]; it found that Latino immigrants perceived that their diet and physical activity levels had been healthier in their home countries. They recalled having eaten more fresh fruits and vegetables, which were easier to obtain, and fewer processed and fast foods, as well as eating smaller portion sizes; they had walked or cycled for transportation before coming to the United States but had begun to drive after immigrating [12]. 
One highly effective means of enhancing culturally appropriate programs and receptivity among participants is the use of community health workers (CHWs), or promotores. CHWs have served as effective health educators in lifestyle behavior interventions tailored for the Latino community [13]. However, few studies have used the perceptions of first-generation Latino CHWs on obesity to inform the development of a weight-loss intervention. This study sought to better understand the role of immigration in the obesity epidemic by interviewing Latino CHWs working in a community that is more than $50 \%$ Latino and that has a high prevalence of obesity. Their insights may be helpful in informing appropriate and effective interventions to address obesity among Latinos.

\section{Methods}

\subsection{Study Design and Sample}

A qualitative study with two focus group discussions (FGDs) was designed to examine the role of immigration on lifestyle habits related to the development of obesity among Latinos in the San Bernardino County, CA. Latinos comprise more than half of the population in the county [14]. Only $27 \%$ of adults residing in San Bernardino County are considered to have a healthy body weight compared to $35.8 \%$ of adults in California [15]. Furthermore, among counties in California, San Bernardino has the second highest rate of mortality due to diabetes [15]. Focus group participants were all bilingual Latinas between the ages of 31 and 52 (mean age $43 \pm 7.02$ ) recruited via email, Facebook group, and word of mouth. Participation was limited to CHWs who had completed or were going through CHW training program at the San Manuel Gateway College Promotores Academy. Minimal demographic data (age, gender and country of origin) were collected (see Table 1).

\subsection{Data Collection}

The physician research moderators provided a brief introduction and invited participants to offer comments on the role of immigration and acculturation of obesity in the Latino community. FGDs took place in the conference room of the San Manuel Gateway College and lasted between 45 and 55 minutes. One was conducted in Spanish and the other in English. A semi-structured interview guide was used and developed based on the grounded theory approach. Each CHW received a \$20 gift card for their participation.

In addition to providing consent for participation in the outcome evaluation of the intervention, prior to the interviews and FGDs, participants read and signed an informed consent form in Spanish, approved by the Loma Linda University Institutional Review Board. Confidentiality was protected by de-identifying participants'.

\subsection{Data Analysis}

Both FGDs were audio recorded. One was transcribed verbatim in English and the other was translated and transcribed in English by a bilingual interviewer. Transcripts were reviewed and systematically coded by two individuals trained in qualitative methods who

Table 1 Sociodemographics for San Bernardino County and select other counties in Southern California (San Bernardino, Riverside, San Diego, Los Angeles and Orange).

\begin{tabular}{lllll}
\hline County & \% Latinos & $\begin{array}{l}\text { Obesity rates (BMI }< \\
27.5)\end{array}$ & \% Foreign-born persons & \% Persons below poverty level \\
\hline San Bernardino & $52.8 \%$ & $63.5 \%$ & $21.3 \%$ & $17.6 \%$ \\
Riverside & $48.4 \%$ & $55.5 \%$ & $21.9 \%$ & $15.3 \%$ \\
San Diego & $33.5 \%$ & $55 \%$ & $23.5 \%$ & $12.4 \%$ \\
Los Angeles & $48.5 \%$ & $56.9 \%$ & $34.5 \%$ & $16.3 \%$ \\
Orange & $34.3 \%$ & $42.2 \%$ & $30.4 \%$ & $11.1 \%$ \\
\hline
\end{tabular}


Table 2 Participant demographics.

\begin{tabular}{lc}
\hline Characteristics & $\mathrm{N}(\%)$ or mean $( \pm \mathrm{SD})$ \\
\hline Age/yrs & $43( \pm 7.02)$ \\
Gender & 15 \\
$\quad$ Female & $15(100 \%)$ \\
Countries of origin & 15 \\
$\quad$ Mexico & $10(66.7 \%)$ \\
Central America & $3(20.1 \%)$ \\
South America & $2(13.4 \%)$ \\
\hline
\end{tabular}

developed an a priori code book with codes aligned with the study framework method. Critical quotes were extracted and aligned with emerging themes using the computer software program MAXQDA 2017. Content analysis was used to identify common themes and similar phrases. Qualitative data are presented below, using direct quotes from community health workers to illustrate findings.

\section{Results}

Participants' socio-demographic information is reported in Table 2. Participants reported that immigration brought about drastic lifestyle changes that had led them and their families to develop new behavioral patterns. Over a period of several months, these behavioral changes would result in weight gain. Three specific mechanisms emerged as being responsible for the behavioral changes: a reduction in the need and time available, for physical activity; a sudden increase in access to unhealthy food; and an abrupt reduction in access and affordability to healthy food choices. The sections below provide more details about these themes as well as participant comments on them.

Theme 1. Reduced need, and time, for physical activity.

Participants shared that-due to more transportation options in the United States and sometimes longer distances between their homes and their destinations - they no longer needed to walk or use a bicycle to run errands, go to school, or go to work. Instead, they used cars or public transportation. They remembered being far more active before they immigrated:
[Back in Mexico] I walked a lot. We didn't have a car... So, [I walked] long distance-for school, for everything.

Another reason given for less physical activity was that they could afford other means of transportation after migrating into this country, making walking unnecessary.

When one was in one's country [Mexico], there was no money to buy a stroller and everything was around the corner. Not here. Here you need a vehicle.

Participants also described their schedules post-immigration as a reason for lowered physical activities:

With the busy schedules we have, who wants to get up at 5AM to exercise? Nobody!

Theme 2. Increased access to food, especially unhealthy food options.

Participants recalled being overwhelmed by the quantity and variety of food available when they first arrived in the United States. This caused them to indulge much more in eating than they would have otherwise done.

"When I moved to this country [from Guatemala], with the change in eating habits, I gained weight."

Here I had access to so many options I started eating too much food.

This is a country of super large portions and I think this plays a role.

Participants also mentioned an increase in meal frequency after migrating to the United States:

We ate only three meals a day; no snacks or chips.

"...having too much food in the house-Eating, eating, eating, eating all the time.” 
Participants also referenced the low cost of high density foods and sugar-sweetened beverages in contrast to their countries of origin. They described taking on a new habit without realizing it for months:

In [Mexico], sparkling mineral water costs three pesos and Coca Cola costs 28 pesos. I came to this country and found out that mineral water cost one dollar and Coca Cola cost one dollar. Of course I drank Coca Cola like crazy the first few months. And then I said "Wait! What am I doing to myself?” But I had already spent a year drinking Coke, Coke, and Coke.

You bring a child into this country and you can buy him all the candy you want. You go to the 99 cents store and it's full of things... So, of course, if you never ate those things in your country of origin (Uruguay), you're going to eat them with the child.

As with not having time for physical activity, participants said that busyness made it difficult to prepare healthy meals:

In this country people work too much. Everyone is always running, running, running. No. Food planning comes down to taking things out, washing things, washing more things, dirtying dishes, washing until everything is clean.... So, just thinking of all the work involved one sometimes prefers to just buy food somewhere else.

Some participants felt that the anxiety associated with immigration had increased their propensity to eat high density foods:

One ends up eating sweets to deal with the anxiety of moving into this country and not finding a job.

Theme 3. Reduced access to healthy food choices.

Lastly, several participants felt that healthy food choices, in particular fresh fruits and vegetables, which had been available either in their own family orchards and gardens or at local markets back in their home countries, were difficult to obtain in the United States. The fruits and vegetables they could find were rarely fresh or in good condition, and exceptions were too expensive.
In [Mexico] my source of sugar was mangoes, watermelon, oranges-fruits! One would grab fresh fruit directly from the tree or from buckets. Not in this country. Here fruit is very expensive.... You buy a watermelon because it's supposedly on special and it's rotten inside. So one has to go to stores with more-you know - that are more prestigious just to get better quality fruits. So, this is what comes out costly.

(Eating healthy) Is definitely out of reach for us. Sometimes we try, but eating healthy is expensive.

\section{Discussion}

The results of this study indicate that immigration plays a significant role in development of obesity for newly migrated Latinos. This finding is similar to the study done by Gomel and his colleagues [16] who interviewed Latino immigrants and found that migration influenced physical activity and dietary behaviors. Participants' perceptions of the negative effects that migration played on their diet and physical activity mirrors previous findings.

One popular hypothesis, known as the "Latino/Immigrant Health paradox," proposes that Latinos have a relative health advantage because they partake in more favorable health behaviors than non-Latino whites [17]. Our findings related to diet and BMIs of Latino immigrants did not support the health behavior hypothesis.

Our participants reported abrupt weight gain after the first few months of living in the United States. Increased access to unhealthy food, reduction in access and affordability to healthy food options, and less time to prepare meals were all factors contributing to their change in dietary behavior after immigration. With regard to exercise, participants recalled expressed high levels of physical activity that had drastically reduced after migration. They furthermore described an increased use of vehicles for transportation in the United States. Although Latino immigrants may engage in less overall physical activity related to 
exercise, it would be premature to conclude their overall activity is reduced due to immigration. Data do show Latinos are overrepresented in physically demanding occupations, and they engage in five or more hours of paid/unpaid work with high levels of arduous labor daily [18].

Limitations of this study include a lack of information on participants' actual weight status and the small number of focus groups participants, which may limit generalizability. A strength of this study, however, was the diverse countries represented among the focus group participants, and their knowledge of the individuals and communities due to their experience as CHWs.

\section{Conclusion}

Our findings indicate that Latino immigrants have a higher likelihood of developing obesity and obesity-related illnesses due to a reduced need for and available amount of time for physical activity, increased access to food, especially unhealthy options, and a reduced access to healthy food choices. Implementation of culturally appropriate interventions using CHWs can bridge cultural and language barriers many newly migrated Latinos face in retaining a healthier weight over the years [19]. Increased awareness of immigration-related challenges and targeting of populations with large immigrant populations remains of vital importance.

Further research should address the differences in leisure-time physical activity compared to physical activity for work or daily tasks, and the impacts of those changes on the health of Latinos due to immigration. To combat the effects of these factors on Latino immigrants, culturally-appropriate interventions should be put into place to increase awareness of obesogenic factors that this population may disproportionately encounter. Early intervention, beginning soon after immigration, and before unhealthy habits are formed, may prove to be one of the most effective preventive solutions.

\section{Acknowledgements}

Research reported in this publication was partially supported by the Ardmore Institute of Health.

\section{References}

[1] Centers for Disease Control and Prevention (CDC). 2017. Adult Obesity Facts. https://www.cdc.gov/obesity/data/adult.html.

[2] Greaney, M. L., Lees, F. D., Lynch, B., Sebelia, L., and Greene, G. 2012. “Using Focus Groups to Identify Factors Affecting Healthful Weight Maintenance in Latino Immigrants.” J NutrEducBehav 44 (5): 448-53.

[3] Goel, M., McCarthy, E. P., Phillip, R. S., and Wee, C. C. 2004. "Obesity among US Immigrant Subgroups by Duration of Residence.” Jama 292 (23): 2860-7.

[4] Guzman, C. E. V., and Sanchez, G. R. 2018. “The Impact of Acculturation and Racialization on Self-rated Status among US Latinos.” J Immigr Minor Health 20 (101):1-7.

[5] Albarran, C. R., Heilemann, M. V., and Koniak-Griffin, D. 2014. "Promotoras as Facilitators of Change: Latinas' Perspectives after Participating in a Lifestyle Behaviour Intervention Program.” J AdvNurs.70 (10): 2303-13.

[6] McLeod, D. L., Bates, C. R., Heard, A. M., Bohnert, A. M., and Santiago, C. D. 2017. "Parent Perceptions of Child Weight Status in Mexican-origin Immigrant Families: An Investigation of Acculturation, Stress and Coping Factors.” J ImmigrMinor Health 20: 441-7.

[7] Hayashi, T., Farrell, M. A., Chaput, L. A., Rochas, D. A., and Hernandez, M. 2010. "Lifestyle Intervention, Behavioral Changes, and Improvement in Cardiovascular Risk Profiles in the California WISEWOMAN Project.” $J$ Women's Health 19 (6): 1129-38.

[8] Brown, A., and Stepler, R. 2017. "Statistical Portrait of the Foreign-born Population in the United States." Pew Research Center Hispanic Trends. http://www.pewhis-panic.org/files/2015/09/Statistical-Por trait-of-the-Foreign-Born-2013_09-2015.pdfl.

[9] Sadeghi, B., Schaefer, S., Tseregounis, I., Alberto, L., Martinez, L., Gomez-Camacho, R., Shaikh, U., Munoz, M., Whent, L., and de la Torre, A. 2017. "Prevalence and Perception of Childhood Obesity in California's Farmworker Communities.” J Community Health 42 (2): 377-84.

[10] Abraido-Lanza, A. F., Chao, M. T., and Florez, K. R. 2005. "Do Healthy Behaviors Decline with Greater Acculturation? Implications for the Latino Mortality Paradox.” SocSci Med 61: 1234-55.

[11] Rosas, L. G., Thiyagarajan, S., Goldstein, B. A., Drieling, R. L., Romero, P. P., Ma, J., Yank, V., and Staffor, R. S. 2015. "The Effectiveness of Two Community-based 
Weight Loss Strategies among Obese, Low-income US Latinos.” J AcadNutr Diet 115 (4): 537-50.

[12] US Census Bureau. 2010. Community Facts. Hispanic or Latino by Type: 2010, 2010 Census Summary File 1. https://factfinder.census.gov/faces/tableservices/jsf/pages/ productview.xhtml?src=CF.

[13] Agne, A. A., Daubert, R., Munoz, M., Scarinci, I., and Cherrington, A. L. 2012. "The Cultural Context of Obesity: Exploring Perceptions of Obesity and Weight Loss among Latina Immigrants.” J Immigr Health 14 (6): 1-14.

[14] National Institutes of Health. 1998. “Clinical Guidelines on the Identification, Evaluation, and Treatment of Overweight and Obesity in Adults-The Evidence Report.” Obes. Res 6Suppl 2: 51S-209S.

[15] Data USA. 2014. County Health State Profiles: San Bernardino

County, https://datausa.io/profile/geo/san-bernardino-county-ca/.

[16] Gomel, J. N., and Zamora, A. 2007. "English-and Spanish-speaking Latina Mothers' Beliefs about Food, Health, and Mothering." J Immigr Minor Health 9: 359-67.

[17] Wolin, K. Y., Colangelo, L. A., Chiu, B. C., and Gapstur, S. M. 2009. "Obesity and Immigration among Latina Women.” J Immigr Mino Health 11 (5): 428-31.

[18] Brown, A., and Stepler, R. 2017. "Statistical Portrait of the Foreign-born Population in the United States." Pew Research Center Hispanic Trends. http://www.pewhis-panic.org/files/2015/09/Statistical-Por trait-of-the-Foreign-Born-2013_09-2015.pdfl.

[19] Goel, M., McCarthy, E. P., Phillip, R. S., and Wee, C. C. 2004. "Obesity among us Immigrant Subgroups by Duration of Residence.” Jama 292 (23): 2860-7. 